\title{
Appendix 19: Mock Examination Answers
}

\begin{tabular}{|c|c|c|c|c|c|}
\hline 1. (a) & 16. (b) & 31. (b) & 46. (b) & 61. (b) & 76. (d) \\
\hline 2. (b) & 17. (c) & 32. (a) & 47. (b) & 62. (b) & 77. (a) \\
\hline 3. (b) & 18. (b) & 33. (b) & 48. (e) & 63. (b) & 78. (b) \\
\hline 4. (b) & 19. (b) & 34. (c) & 49. (c) & 64. (b) & 79. (d) \\
\hline 5. (d) & 20. (b) & 35. (b) & 50. (d) & 65. (c) & 80. (d) \\
\hline 6. (b) & 21. (b) & 36. (d) & 51. (a) & 66. (c) & 81. (e) \\
\hline 7. (c) & 22. (b) & 37. (b) & 52. (c) & 67. (d) & 82. (d) \\
\hline 8. (b) & 23. (b) & 38. (b) & 53. (a) & 68. (d) & 83. (c) \\
\hline 9. (d) & 24. (a) & 39. (b) & 54. (b) & 69. (c) & 84. (d) \\
\hline 10. (c) & 25. (d) & 40. (a) & 55. (d) & 70. (a) & 85. (c) \\
\hline 11. (c) & 26. (b) & 41. (b) & 56. (d) & 71. (c) & 86. (a) \\
\hline 12. (b) & 27. (e) & 42. (d) & 57. (c) & 72. (c) & 87. (d) \\
\hline 13. (b) & 28. (b) & 43. (a) & 58. (a) & 73. (c) & 88. (b) \\
\hline 14. (e) & 29. (e) & 44. (b) & 59. (e) & 74. (a) & 89. (a) \\
\hline 15. (c) & 30. (d) & 45. (a) & 60. (b) & 75. (d) & 90. (a) \\
\hline
\end{tabular}

E. Mantel et al., Nuclear Medicine Technology, https://doi.org/10.1007/978-3-319-62500-3_37, (C) Springer International Publishing AG $20 \overline{1} 8$ 